\title{
Fine needle aspiration biopsy of thyroid nodules
}

\author{
I S Arda, S Yildirim, B Demirhan, S Firat
}

\begin{abstract}
Background-Fine needle aspiration biopsy (FNA) is a routine diagnostic technique for evaluating thyroid nodules. Many reports in adults consider that FNA is superior to thyroid ultrasonography (USG) and radionuclide scanning (RS). Only five studies have been published on FNA of childhood thyroid nodules.

Aims-To investigate the reliability of FNA in the evaluation and management of thyroid nodules, and compare the results of FNA, USG, and RS with regard to final histopathological diagnosis.
\end{abstract}

Methods-FNA was performed in 46 children with thyroid nodules after USG and RS examination. We investigated the sensitivity, specificity, accuracy, and positive and negative predictive values of USG, RS, and FNA in their management.

Results-Six patients who had malignant or suspicious cells on FNA examination underwent immediate surgery. The other 40 patients received medical treatment according to their hormonal status. Fifteen of these nodules either disappeared or decreased in number and/or size. Surgery was performed in 25 patients who did not respond to therapy. Statistical analysis revealed sensitivity, specificity, accuracy, and positive and negative predictive values respectively as follows: $\mathbf{6 0 \%}$, $59 \%, 59 \%, 15 \%$, and $92 \%$ for USG; $30 \%$, $42 \%, 39 \%, 12 \%$, and $68 \%$ for SC; $100 \%$, $95 \%, 95 \%, 67 \%$, and $100 \%$ for FNAB.

Conclusion-FNAB is as reliable in children as in adults for definitive diagnosis of thyroid nodules. Using this technique avoids unnecessary thyroid surgery in children.

(Arch Dis Child 2001;85:313-317)

Keywords: fine needle aspiration; biopsy; thyroid nodule

Baskent University Faculty of Medicine, Department of Pediatric Surgery, Fevzi Çakmak caddesi 10. sokak No: 45,06490 Bahçelievler Ankara, Turkey

I S Arda

$S$ Yildirim

B Demirhan

Social Security

Hospital Ankara

Children Hospital,

Division of Pediatrics

S Firat

Correspondence to:

Prof. Serdar

serdara@baskent-ank.edu.tr

Accepted 25 June 2001
The technique has been used less extensively in children. ${ }^{10-12}$ To date, only five papers pubished in English have documented series involving the use of FNA for diagnosing thyroid nodules in children. ${ }^{13-17}$ We investigated the reliability of FNA in evaluating and managing thyroid nodules, and assessed the overall usefulness of the method.

\section{Patients and methods}

Our prospective study included 46 children who presented with nodules in their thyroid glands during a six year period. All nodules were fine needle biopsied after USG imaging and RS examination with 99m-technetium pertechnetate. The same surgeon (ISA) performed aspirations in all cases. Patients were placed in the recumbent position with a pillow under their shoulders, such that their neck was hyperextended, and the skin cleansed with povidone iodine (Betadine scrub). Local anaesthetic was not used routinely, but we have used prilocaine hydrochloride (Citanest) in uncooperative patients or in the case of inadequate material. In children with multiple nodules, we attempted to biopsy the largest one. The nodule was fixed in position manually, and a 23 gauge needle attached to a $20 \mathrm{ml}$ disposable syringe inserted perpendicular to the anterior surface of the neck. Once the needle was in place, constant suction was applied and maintained while the needle was withdrawn to the level of the nodule capsule. The content was then discharged onto glass slides and smears were made. If no sample was drawn into the syringe on the first attempt, the needle was inserted in a different direction to obtain adequate material without withholding it outside the skin. We have prepared at least five smears similar to the technique for preparation of bone marrow aspirates. All smears were dried in air and Giemsa stained (Merck Laboratories, Germany). One cytopathologist evaluated the smears. The presence of more than seven groups of cells per stained smear was considered sufficient aspirate volume. FNA examination results were classified according to cell type-benign, malignant, or follicular pattern. Biopsy specimens were labelled suspicious when cell types could not be determined.

After obtaining the results of FNA examination, we administered thyroid hormone or antithyroid drugs to patients as appropriate except in those in whom we detected malignant or suspicious cells. These patients underwent immediate surgery. After six months of treatment, the nodules were re-evaluated by physical examination, USG, and RS. Patients whose nodules were the same size or had enlarged underwent surgery. Maintaining high concentrations of thyroid hormones despite therapy was another indication for surgery. We performed intraoperative frozen section examination (FSE) in patients both with solid nodules 
Table 1 Definition and calculation of the statistical parameters

\begin{tabular}{|c|c|c|c|c|c|}
\hline Type & \multicolumn{2}{|l|}{ Cytology } & $U S G$ & Scintigraphy & Histopathology \\
\hline $\mathrm{TP}$ & \multicolumn{2}{|c|}{ Malignant or suspicious } & Solid & Cold & Malignant \\
\hline $\mathrm{TN}$ & \multicolumn{2}{|c|}{ Benign cells } & Cystic or mixed & Hot or warm & Benign \\
\hline FP & \multicolumn{2}{|c|}{ Malignant or suspicious } & Solid & Cold & Benign \\
\hline $\mathrm{FN}$ & \multicolumn{2}{|c|}{ Benign cells } & Cystic or mixed & Hot or warm & Malignant \\
\hline \multicolumn{2}{|c|}{ Sensitivity } & \multicolumn{3}{|c|}{$=\mathrm{TP} /(\mathrm{TP}+\mathrm{FN})$} & \\
\hline \multirow{2}{*}{\multicolumn{2}{|c|}{$\begin{array}{l}\text { Specificity } \\
\text { Accuracy }\end{array}$}} & \multicolumn{3}{|c|}{$=\mathrm{TN} /(\mathrm{TN}+\mathrm{FP})$} & \\
\hline & & \multicolumn{3}{|c|}{$=(\mathrm{TP}+\mathrm{TN}) /(\mathrm{TP}+\mathrm{TN}+\mathrm{FP}+\mathrm{FN})$} & \\
\hline \multicolumn{2}{|c|}{ Positive predictive value } & \multicolumn{3}{|c|}{$=\mathrm{TP} /(\mathrm{TP}+\mathrm{FP})$} & \\
\hline \multicolumn{2}{|c|}{ Negative predictive value } & \multicolumn{3}{|c|}{$=\mathrm{TN} /(\mathrm{TN}+\mathrm{FN})$} & \\
\hline
\end{tabular}

USG, thyroid ultrasonography; TP, true positive; TN, true negative; $\mathrm{FP}$, false positive; $\mathrm{FN}$, false negative.

and with malignant or suspicious cells in their FNAs. We also performed FSE in two patients whose FNA was unsuccessful. All removed thyroid glands were evaluated histopathologically. Patients with nodules who did not undergo surgery were followed at three month intervals during hormonal treatment. Their thyroid glands were examined once a year after the cessation of drugs. The follow up period ranged from one to five years.

At the end of the study, we calculated the sensitivity, specificity, accuracy, and positive and negative predictive values of thyroid USG, $\mathrm{RS}$, and FNA results in the diagnosis of thyroid nodules of children (see table 1). We derived these figures using the final histopathological diagnosis as the gold standard.

\section{Results}

Nine patients were male (19\%) and 37 female (81\%). Mean age was 9 years (range 5-116). Diameters of the biopsied nodules were as follows: six (13\%) were less than $1 \mathrm{~cm}, 28(61 \%)$ were between 1 and $2 \mathrm{~cm}$, and $12(26 \%)$ were larger than $2 \mathrm{~cm}$. We were able to aspirate adequate material in 44 of 46 patients (96\%). In the two cases where we were unsuccessful, nodule sizes were 1 and $1.5 \mathrm{~cm}$. Only four patients $(9 \%)$ required multiple attempts; all had a nodule diameter of less than $1 \mathrm{~cm}$. Although we did not use local anaesthesia routinely, six patients (13\%) needed subcutaneous administration of prilocaine hydrochloride. In four the first attempt was unsuccessful. The other two were straining. All the other patients' aspirations were successful at the first attempt.

Table 2 presents results of USG, RS, and FNA. In the surgically treated group we detected 17 solid, 10 mixed, and four cystic nodules with USG. RS revealed 19 cold, six hot, and six warm nodules. Results of FNA

Table 2 Comparative results of patients undergoing surgical and medical treatment

\begin{tabular}{|c|c|c|c|c|c|c|c|c|c|c|}
\hline Case & Sex & $U S G$ & Type & $R S$ & Type & FSE & $F N A$ & Type & Surgery & Histopathology \\
\hline \multicolumn{11}{|c|}{ Patients undergoing surgical treatment } \\
\hline 1 & $\mathrm{~F}$ & Solid, solitary & FP & Cold & FP & Benign & Follicular & $\mathrm{TN}$ & RST & Follicular adenoma \\
\hline 2 & M & Mixed, multiple & $\mathrm{TN}$ & Hot & $\mathrm{TN}$ & Benign & Unsuccessful & - & BST & Follicular adenoma \\
\hline 3 & $\mathrm{~F}$ & Solid, solitary & $\mathrm{TP}$ & Cold & $\mathrm{TP}$ & Malignant & Malignant & $\mathrm{TP}$ & BTT & Papillary carcinoma \\
\hline 4 & $\mathrm{~F}$ & Solid, multiple & $\mathrm{FP}$ & Cold & FP & Benign & Suspicious & $\mathrm{FP}$ & BST & Colloidal goitre \\
\hline 5 & $\mathrm{~F}$ & Solid, solitary & $\mathrm{TP}$ & Cold & $\mathrm{TP}$ & Malignant & Malignant & $\mathrm{TP}$ & BTT & Papillary carcinoma \\
\hline 6 & $M$ & Solid, multiple & TP & Cold & $\mathrm{TP}$ & Malignant & Suspicious & $\mathrm{TP}$ & BTT & Follicular carcinoma \\
\hline 7 & $\mathrm{~F}$ & Solid, solitary & FP & Cold & FP & Benign & Benign & $\mathrm{TN}$ & RST & Colloidal goitre \\
\hline 8 & $\mathrm{~F}$ & Solid, solitary & FP & Cold & FP & Benign & Benign & $\mathrm{TN}$ & LST & Colloidal goitre \\
\hline 9 & $\mathrm{~F}$ & Solid, solitary & FP & Cold & FP & Benign & Benign & $\mathrm{TN}$ & RST & Colloidal goitre \\
\hline 10 & $\mathrm{~F}$ & Mixed, multiple & $\mathrm{FN}$ & Hot & $\mathrm{FN}$ & Malignant & NHL cells & $\mathrm{TP}$ & BTT & NHL metastasis \\
\hline 11 & $\mathrm{~F}$ & Solid, solitary & $\mathrm{FP}$ & Cold & $\mathrm{FP}$ & Benign & Follicular & $\mathrm{TN}$ & RST & Follicular adenoma \\
\hline 12 & $\mathrm{~F}$ & Solid, multiple & FP & Cold & FP & Benign & Benign & $\mathrm{TN}$ & BST & Colloidal goitre \\
\hline 13 & $\mathrm{~F}$ & Solid, solitary & FP & Hot & $\mathrm{TN}$ & Benign & Benign & $\mathrm{TN}$ & RST & Colloidal goitre \\
\hline 14 & $\mathrm{~F}$ & Solid, solitary & FP & Warm & $\mathrm{TN}$ & Benign & Unsuccessful & - & RST & Follicular adenoma \\
\hline 15 & $\mathrm{~F}$ & Solid, solitary & FP & Hot & $\mathrm{FN}$ & Benign & Benign & $\mathrm{TN}$ & LST & Colloidal goitre \\
\hline 16 & $\mathrm{~F}$ & Solid, solitary & FP & Hot & $\mathrm{TN}$ & Benign & Follicular & $\mathrm{TN}$ & RST & Follicular adenoma \\
\hline 17 & $\mathrm{~F}$ & Solid, solitary & FP & Warm & $\mathrm{TN}$ & Benign & Benign & $\mathrm{TN}$ & LST & Colloidal goitre \\
\hline 18 & $\mathrm{~F}$ & Mixed, multiple & $\mathrm{TN}$ & Cold & FP & Benign & Suspicious & FP & BST & Follicular adenoma \\
\hline 19 & $\mathrm{~F}$ & Solid, multiple & FP & Cold & FP & Benign & Benign & $\mathrm{TN}$ & BST & Colloidal goitre \\
\hline 20 & $\mathrm{~F}$ & Solid, multiple & FP & Cold & FP & Benign & Benign & $\mathrm{TN}$ & BST & Colloidal goitre \\
\hline 21 & $\mathrm{~F}$ & Mixed, multiple & $\mathrm{TN}$ & Warm & $\mathrm{TN}$ & - & Benign & $\mathrm{TN}$ & BST & Follicular adenoma \\
\hline 22 & $\mathrm{~F}$ & Mixed, multiple & $\mathrm{TN}$ & Warm & $\mathrm{TN}$ & - & Follicular & $\mathrm{TN}$ & RST & Follicular adenoma \\
\hline 23 & $\mathrm{~F}$ & Cystic, multiple & TN & Cold & $\mathrm{FP}$ & - & Benign & $\mathrm{TN}$ & BST & Colloidal goitre \\
\hline 24 & $\mathrm{~F}$ & Mixed, multiple & $\mathrm{TN}$ & Cold & FP & - & Benign & $\mathrm{TN}$ & BST & Colloidal goitre \\
\hline 25 & M & Mixed, multiple & $\mathrm{TN}$ & Warm & $\mathrm{TN}$ & - & Benign & $\mathrm{TN}$ & BST & Follicular adenoma \\
\hline 26 & $\mathrm{~F}$ & Mixed, solitary & $\mathrm{TN}$ & Cold & $\mathrm{FP}$ & - & Benign & $\mathrm{TN}$ & LST & Colloidal goitre \\
\hline 27 & $\mathrm{~F}$ & Mixed, multiple & $\mathrm{TN}$ & Warm & $\mathrm{TN}$ & - & Benign & $\mathrm{TN}$ & BST & Colloidal goitre \\
\hline 28 & $\mathrm{~F}$ & Cystic, multiple & $\mathrm{FN}$ & Cold & FP & - & Benign & $\mathrm{TN}$ & BST & Colloidal goitre \\
\hline 29 & $M$ & Cystic, solitary & $\mathrm{TN}$ & Cold & FP & - & Follicular & $\mathrm{TN}$ & LST & Follicular adenoma \\
\hline 30 & M & Mixed, solitary & $\mathrm{TN}$ & Cold & FP & - & Benign & $\mathrm{TN}$ & RST & Colloidal goitre \\
\hline 31 & $\mathrm{~F}$ & Cystic, solitary & $\mathrm{TN}$ & Hot & $\mathrm{FN}$ & - & Benign & $\mathrm{TN}$ & RST & Follicular adenoma \\
\hline \multicolumn{11}{|c|}{ Patients undergoing medical treatment } \\
\hline 1 & $\mathrm{~F}$ & Mixed, multiple & $\mathrm{TN}$ & Cold & FP & - & Benign & $\mathrm{TN}$ & - & Colloidal goitre \\
\hline 2 & $\mathrm{~F}$ & Solid, solitary & $\mathrm{FP}$ & Hot & $\mathrm{FN}$ & - & Benign & $\mathrm{TN}$ & - & Colloidal goitre \\
\hline 3 & M & Mixed, multiple & TN & Cold & FP & - & Benign & $\mathrm{TN}$ & - & Colloidal goitre \\
\hline 4 & M & Mixed, multiple & $\mathrm{TN}$ & Cold & FP & - & Benign & $\mathrm{TN}$ & - & Colloidal goitre \\
\hline 5 & $\mathrm{~F}$ & Solid, solitary & $\mathrm{FP}$ & Warm & TN & - & Benign & $\mathrm{TN}$ & - & Colloidal goitre \\
\hline 6 & $\mathrm{~F}$ & Cystic, solitary & $\mathrm{TN}$ & Cold & $\mathrm{FP}$ & - & Benign & $\mathrm{TN}$ & - & Colloidal goitre \\
\hline 7 & $\mathrm{~F}$ & Cystic, solitary & $\mathrm{TN}$ & Warm & $\mathrm{TN}$ & - & Benign & $\mathrm{TN}$ & - & Colloidal goitre \\
\hline 8 & $\mathrm{~F}$ & Mixed, multiple & $\mathrm{TN}$ & Cold & FP & - & Benign & $\mathrm{TN}$ & - & Colloidal goitre \\
\hline 9 & $\mathrm{~F}$ & Mixed, multiple & $\mathrm{TN}$ & Warm & $\mathrm{TN}$ & - & Benign & $\mathrm{TN}$ & - & Colloidal goitre \\
\hline 10 & $\mathrm{~F}$ & Solid, solitary & $\mathrm{FP}$ & Warm & $\mathrm{TN}$ & - & Benign & $\mathrm{TN}$ & - & Colloidal goitre \\
\hline 11 & $\mathrm{~F}$ & Cystic, solitary & $\mathrm{TN}$ & Hot & $\mathrm{FN}$ & - & Benign & $\mathrm{TN}$ & - & Colloidal goitre \\
\hline 12 & $M$ & Mixed, solitary & $\mathrm{TN}$ & Hot & $\mathrm{FN}$ & - & Benign & $\mathrm{TN}$ & - & Colloidal goitre \\
\hline 13 & $\mathrm{~F}$ & Mixed, multiple & $\mathrm{TN}$ & Warm & $\mathrm{TN}$ & - & Benign & $\mathrm{TN}$ & - & Colloidal goitre \\
\hline 14 & M & Cystic, solitary & $\mathrm{TN}$ & Warm & TN & - & Benign & TN & - & Colloidal goitre \\
\hline 15 & $\mathrm{~F}$ & Cystic, solitary & $\mathrm{TN}$ & Hot & $\mathrm{FN}$ & - & Benign & $\mathrm{TN}$ & - & Colloidal goitre \\
\hline
\end{tabular}

F, female; M, male; TP, true positive; TN, true negative; FP, false positive; FN, false negative; BTT, bilateral total thyroidectomy; BST, bilateral subtotal thyroidectomy; RST, right subtotal thyroidectomy; LST, left subtotal thyroidectomy; NHL, non-Hodgkin lymphoma. 
Table 3 Statistical analysis of the results

\begin{tabular}{lrrrr}
\hline & USG & \multicolumn{1}{c}{ RS } & FNA & \multicolumn{1}{c}{ FSE } \\
\hline True positive & 3 & 4 & 3 & 4 \\
True negative & 15 & 38 & 24 & 15 \\
False positive & 21 & 2 & 17 & 1 \\
False negative & 7 & 0 & 2 & 0 \\
Sensitivity & $60 \%$ & $30 \%$ & $100 \%$ & $100 \%$ \\
Specificity & $59 \%$ & $42 \%$ & $95 \%$ & $94 \%$ \\
Accuracy & $59 \%$ & $39 \%$ & $95 \%$ & $95 \%$ \\
Positive predictive value & $15 \%$ & $12 \%$ & $67 \%$ & $80 \%$ \\
Negative predictive value & $92 \%$ & $68 \%$ & $100 \%$ & $100 \%$ \\
\hline
\end{tabular}

examination were as follows: malignant cells in two patients, metastatic non-Hodgkin lymphoma (NHL) cells in one, benign cells in 18 , follicular pattern in five, and suspicious cells in three. FNA was unsuccessful in two patients. In the medically treated group, nodules were solid in eight, mixed in five, and cystic in two patients with USG; and cold in 12 , hot in two, and warm in one patient with RS. All biopsies revealed benign cells on FNA examination of these patients.

Following the FNA examination results, we operated immediately on six patients (13\%) who had malignant, metastatic NHL and suspicious cells. While malignant aspirations showed papillary carcinoma in the final histopathological examinations, three of the patients with suspicious cells were confirmed as having follicular carcinoma, follicular adenoma, and colloidal goitre, respectively. Fifteen patients $(33 \%)$ responded to medical treatment over a six month period. We have operated on 25 (54\%) unresponsive patients. The indications for surgery were no change or enlargement in nodule size in 23 patients, and high concentrations of thyroid hormones despite treatment in two patients. No patient responding to medical treatment developed recurrent nodules or malignancy after treatment stopped.

We performed FSE in 20 patients: 12 with solid nodules, three with suspicious cells, two with malignant cells, one with metastatic NHL cells, and two whose FNAs were unsuccessful. All patients with solid nodules had benign cells in their FNAs. One patient with suspicious cells, one patient with metastatic NHL cells, and two patients with malignant cells on FNA had features of malignancy in their FSE. The other four patients' examinations revealed a benign lesion. Table 2 presents the results of FSE and final histopathological diagnoses of nodules. Table 3 presents the results of statistical analysis.

\section{Discussion}

RS examination has been the first choice for diagnosing thyroid nodules in the past, but the technique has significant limitations in children. ${ }^{2}{ }^{2}$ It is primarily useful for detecting ectopic tissues or hot toxic nodules. ${ }^{18}{ }^{19}$ The other well known diagnostic method, USG, is of limited value, especially for evaluating children with solitary thyroid nodules. ${ }^{20}{ }^{21}$ The popular fine needle biopsy technique, introduced in the 1950s in Scandinavia, provides adequate specimens for cytological examination. ${ }^{22}$ The accuracy of diagnosis by FNA is dependent on the type and diameter of the lesion being sampled and the experience of those doing the sampling and evaluating the smears. ${ }^{23}{ }^{24}$ Although there appears to be no uniformity of the operative technique in performing FNA, we think our technique with a 23 gauge needle and constant suction provides adequate material for examination.

The main objective of FNA is to identify thyroid nodules that can safely be left in situ, excluding carcinoma. Before the introduction of FNA, patients with solid, cold, and/or single nodules had been candidates for surgery. In practice, diagnosis based on FNA has led to a substantial reduction in the number of patients sent to surgery. ${ }^{65}$ In the current series, of 40 patients with benign or follicular cells, 21 had solid, 31 had cold, and 23 had solitary nodules. No patient either operated or not operated developed cancer at the time of operation or during follow up. As reported in recent childhood series, ${ }^{13} 16$ we believe that FNA significantly narrows the scope of indications for surgery in children with thyroid nodules.

Correct diagnosis can be achieved in over $90 \%$ of undifferentiated, medullary, and papillary carcinomas using FNA. ${ }^{7}$ These patients need no other investigation of the nodule and should be operated on without delay. If suspicious cells are detected, surgical excision of the nodule should be the treatment of choice to exclude malignancy. ${ }^{26} 27$ In our series, of three patients with suspicious cells, two proved benign and one had follicular carcinoma. Accuracy of the technique in cases of follicular carcinoma is approximately $40 \%$ because of difficulty in diagnosing this neoplasm based on FNA alone. ${ }^{23}{ }^{28}$ We believe that surgery aims not only at treatment but also to be the optimal way to make a diagnosis in patients with a suspicious result on FNA examination. Some recommend repeating aspirations in patients with persistent nodularity in case of carcinoma development later in life. ${ }^{29}$ In our study, we detected no malignancy in the final histopathological examinations of the surgically treated patients nor in patients with benign FNA receiving only medical treatment during follow

Table 4 Comparison of the childhood FNA series

\begin{tabular}{|c|c|c|c|c|c|c|c|c|c|c|c|c|c|c|}
\hline \multirow[b]{2}{*}{ Series } & \multirow[b]{2}{*}{ No. } & \multicolumn{2}{|l|}{ Sex } & \multirow[b]{2}{*}{ Age } & \multicolumn{4}{|c|}{ FNA results } & \multirow{2}{*}{$\begin{array}{l}\text { Overall } \\
\text { malignancy } \\
\text { rate }\end{array}$} & \multicolumn{5}{|c|}{ Statistical analysis } \\
\hline & & $M$ & $F$ & & Benign & Malign & Suspicious & Insufficient & & Sen & $S p$ & $A c c$ & $P P V$ & $N P V$ \\
\hline Arda et al & 46 & $9(19 \%)$ & $37(81 \%)$ & 9 & $38(82 \%)$ & $3(7 \%)$ & $3(7 \%)$ & $2(4 \%)$ & $7 \%$ & $100 \%$ & $95 \%$ & $95 \%$ & $67 \%$ & $100 \%$ \\
\hline Al-Shaikh $e t a l^{17}$ & 41 & $35(85 \%)$ & $6(15 \%)$ & 13 & $30(73 \%)$ & $2(5 \%)$ & $6(15 \%)$ & $3(7 \%)$ & $5 \%$ & $87 \%$ & $100 \%$ & $87 \%$ & $29 \%$ & $100 \%$ \\
\hline Khurana et $a l^{16}$ & 57 & $11(19 \%)$ & $46(81 \%)$ & 17 & $36(63 \%)$ & $7(12 \%)$ & $14(25 \%)$ & 0 & $25 \%$ & $93 \%$ & $81 \%$ & $84 \%$ & $62 \%$ & $97 \%$ \\
\hline Lugo-Vicente et $a l^{15}$ & 24 & $4(\% 17)$ & $20(83 \%)$ & 15 & $11(61 \%)$ & $2(11 \%)$ & $2(11 \%)$ & $3(17 \%)$ & $21 \%$ & $60 \%$ & $90 \%$ & $80 \%$ & $75 \%$ & $81 \%$ \\
\hline Degnan et al ${ }^{14}$ & 18 & $4(22 \%)$ & $14(78 \%)$ & 14 & $7(41 \%)$ & $2(12 \%)$ & $7(41 \%)$ & $1(6 \%)$ & $33 \%$ & $73 \%$ & $80 \%$ & $75 \%$ & $89 \%$ & $57 \%$ \\
\hline Raab et $a l^{13}$ & 57 & $8(14 \%)$ & $49(86 \%)$ & 13 & $51(77 \%)$ & $4(6 \%)$ & $8(12 \%)$ & $3(5 \%)$ & $18 \%$ & $80 \%$ & $86 \%$ & $85 \%$ & $36 \%$ & $98 \%$ \\
\hline
\end{tabular}

No., number of patients; M, male; F, female; Sen, sensitivity; Sp, specificity; Acc, accuracy; PPV, positive predictive value; NPV, negative predictive value. 
up. We believe that repeated aspiration is unnecessary in children with benign cells on FNA. However, we advise that persistence or enlargement of nodule size or persistence of high concentrations of thyroid hormones despite medical treatment are indications for surgery.

Recent studies have assessed FNA and perioperative FSE with regard to reliability in the diagnosis of cancer and determining the limitation of excision of the gland. FSE can be omitted if FNA is reported as benign. ${ }^{30}$ When the FNA result is uncertain, patients should undergo diagnostic surgery, and definitive surgery should be based on the FSE result. In our series, we encountered no case in which FNA revealed benign cells but FSE and consequent histopathological examinations detected malignancy. Therefore, we believe that FSE is unnecessary in patients with benign cells on FNA.

An important aspect of FNA in small children is whether sedation or anaesthesia is necessary. We found that inserting a needle for anaesthetic administration caused as much fear and discomfort as insertion of the FNA needle. We consider that local anaesthesia should be reserved for children in whom the first attempt is unsuccessful or if the child is fearful. Anaesthesia spray or cream may be another choice.

The principal reasons why FNA has not been used more widely in children are age, neck size, the need for sedation or anaesthesia, and the amount of specimen needed..$^{15}$ Table 4 compares previous series with ours. It shows that benign nodules significantly outnumber those which are malignant. Although a thyroid nodule in a child involves an underlying risk of malignancy, the majority are benign ${ }^{13}{ }^{15}$ with an overall rate of primary thyroid malignancy of $5-333 \%$. The accuracy in detecting thyroid tumours is $75-995 \%$ with FNA. Our childhood malignancy rate is $7 \%$; we believe the high figure for benign nodules in our series to be a result of the fact that endemic goitre is common in some regions in our country. ${ }^{31}$ As the number of suspicious FNA examinations increases, the accuracy of the technique decreases. Although Degnan et al reported that the accuracy of FNA for diagnosing thyroid malignancy in children was similar to that of other diagnostic procedures, ${ }^{14}$ both in children and adults, ${ }^{4}{ }^{9}{ }^{13-17}$ we conclude that FNA was more reliable than USG and RS in the diagnosis of thyroid nodules. When comparing our results with others, it seems that our sensitivity, specificity, and accuracy is higher. As mentioned above, detection of malignant cells, especially follicular neoplasms, has a higher false positive rate. The number of malignant FNA in our series is less than in other series which helps to explain our better figures.

We conclude that FNA is as reliable a method for assessing thyroid nodules in children as in adults. The technique can be easily applied without local anaesthesia, although this should be used in selected cases such as those who are fearful, or after unsuccessful attempts. FNA prevents unnecessary thyroid surgery in children, whose nodules are more likely to be cold on scintigraphy, solid on ultrasonography, and have a greater tendency to be malignant than those found in adults. We believe that detection of malignant or suspicious cells are definite indications for surgery. FSE should be performed only in patients with malignant or suspicious cells and has no place in patients whose previous FNA examinations revealed benign cells.

1 Sabel MS, Staren ED, Gianakakis LM, et al. Effectiveness of the thyroid scan in evaluation of the solitary thyroid nodule. Am Surg 1997;63:660-3.

2 Kneafsey B, Gillen P, Brady MP. Limitations of thyroid Kneafsey B, Gillen P, Brady MP. Limitations of thyroid
scanning in solitary thyroid nodules. Ir 7 Med Sci 1994;163: 451-4.

3 Garcia CJ, Daneman A, Thorner P, Daneman D. Sonography of multinodular thyroid gland in children and adolescents. Am F Dis Child 1992;146:811-16.

4 Maxwell JG, Scallion RR, White WC, et al. Fine-needle aspiration cytology and thyroid surgery in the community hospital. Am ₹ Surg 1996;172:529-34

5 Garcia-Mayor RV, Perez Mendez LF, Paramo C, et al. Fineneedle aspiration biopsy of thyroid nodules: impact on clinical practice. F Endocrinol Invest 1997;20:482-7.

6 Bouvet M, Feldman JI, Gill GN, et al. Surgical management of the thyroid nodule: patient selection based on the results of fine-needle aspiration cytology. Laryngoscope 1992;102: 1353-6.

7 Piromalli D, Martelli G, Del Prato I, et al. The role of fine needle aspiration in the diagnosis of thyroid nodules: analysis of 795 consecutive cases. F Surg Oncol 1992;50:247-50.

8 Ridgway EC. Clinician's evaluation of a solitary thyroid nodule. F Clin Endocrinol Metab 1992;74:231-55.

9 Lopez LH, Canto JA, Herrera MF, et al. Efficacy of fine-needle aspiration biopsy of thyroid nodules: experience of a Mexican institution. World F Surg 1997;21:40811

10 Silverman JF, Gurley AM, Holbrook CT. Pediatric fineneedle aspiration biopsy. Am f Clin Pathol 1991;95:653-99.

11 Wakely PE Jr, Kardos TF, Frable WJ. Application of fine needle aspiration biopsy to pediatrics. Hum Pathol 1988;19: 1383-6.

12 Verdeguer A, Castel V, Torres V, et al. Fine-needle aspiration biopsy in children: experience in 70 cases. Med Pediatr Oncol 1988;16:98-100.

13 Raab SS, Silverman JF, Elsheikh TM, et al. Pediatric thyroid nodules: disease demographics and clinical management as determined by fine needle aspiration biopsy. Pediatrics 1995;95:46-9.

14 Degnan BM, McClellan DR, Francis GL. An analysis of fine-needle aspiration biopsy of the thyroid in children and fine-needle aspiration biopsy of the thyroid in

15 Lugo-Vicente $\mathrm{H}$, Ortiz VN, Irizarry $\mathrm{H}$, et al. Pediatric thyroid nodules: management in the era of fine needle aspiration. F Pediatr Surg 1998;33:1302-5.

16 Khurana KK, Labrador E, Izquierdo R, et al. The role of fine-needle aspiration biopsy in the management of thyroid nodules in children, adolescents, and young adults: a multi-institutional study. Thyroid 1999;9:383-6.

17 Al-Shaikh A, Ngan B, Daneman A, Daneman D. Fineneedle aspiration biopsy in the management of thyroid nodules in children and adolescents. F Pediatr 2001;138: $140-2$.

18 Cox CA, Nguyen DL, Medina J, Leonard JC. Dermoid cyst presenting as a "cold" thyroid nodule. Clin Nucl Med 1996; 21:395.

19 McHenry CR, Danish R, Murphy T, Marty JJ. Atypical thyroglossal duct cyst: a rare cause for a solitary cold thyroid nodule in children. Am Surg 1993;59:223-8.

20 Garcia CJ, Daneman A, Thorner P, Daneman D. Sonography of multinodular thyroid gland in children and phy of multinodular thyroid gland in ch

21 Garcia CJ, Daneman A, McHugh K, et al. Sonography in thyroid carcinoma in children. Brf Radiol 1992;65:977-82. 2 Söderström N. Puncture of goitres for aspiration biopsy: A preliminary report. Acta Med Scand 1952;144:235-44.

23 Hamburger JI, Hamburger SW. Use of needle biopsy data in diagnosis and management of thyroid nodules. In: Cady B, Rossi RL, eds. Surgery of the thyroid and parathyroid glands. Philedelphia: WB Saunders Co, 1991:92-117.

24 Caraway NP, Sneige N, Samaan NA. Diagnostic pitfalls in thyroid fine-needle aspiration: a review of 394 cases. Diagn Cytopathol 1993;9:345-50.

25 Van Vliet G, Glinoer D, Verelst J, et al. Cold thyroid nodules in childhood: is surgery always necessary? Eur $\mathcal{F}$ Pediatr 1987;146:378-82.

26 McHenry CR, Walfish PG, Rosen IB. Non-diagnostic fine needle aspiration biopsy: a dilemma in management of nodular thyroid disease. Am Surg 1993;59:415-19.

27 Agrawal S. Diagnostic accuracy and role of fine needle aspiration cytology in management of thyroid nodules. F Surg Oncol 1995;58:168-72. 
28 Schlinkert RT, van Heerden JA, Goellner JR, et al. Factors that predict malignant thyroid lesions when fine-needle aspiration is "suspicious for follicular neoplasm". Mayo 72:913-16

29 Aguilar J, Rodriguez JM, Flores B, et al. Value of repeated fine-needle aspiration cytology and cytologic experience on the management of thyroid nodules. Otolaryngol Head Neck Surg 1998;119:121-4
30 Hamming JF, Vriens MR, Goslings BM, et al. Role of fineneedle aspiration biopsy and frozen section examination in determining the extent of thyroidectomy. World f Surg 1998;22:575-9.

31 Ozbakir O, Dogukan A, Kelestimur F. The prevalence of thyroid dysfunction among elderly subjects in an endemic goiter area of Central Anatolia. Endocr F 1995; 42: 713-16.

\section{Rapid responses}

Letters on the following papers have been published recently as rapid responses on the $A D C$ website. To read these letters visit www.archdischild.com and click on "Read eletters"

Liquid paraffin: a reappraisal of its role in the treatment of constipation. F Sharif, E Crushell, K O'Driscoll, et al. Arch Dis Child 2001;85:121-4.

Accidents and resulting injuries in premobile infants: data from the ALSPAC study. S A Warrington, C M Wright, ALSPAC Study Team. Arch Dis Child 2001;85:104-7.

Recent advances in cystic fibrosis. I J M Doull. Arch Dis Child 2001;85:62-66.

Bile bilirubin pigment analysis in disorders of bilirubin metabolism in early infancy. W $S$ Lee, P J McKiernan, S V Beath, et al. Arch Dis Child 2001;85:38-42.

Should infants be screened for anaemia? A prospective study investigating the relation between haemoglobin at 8, 12, and 18 months and development at 18 months. A Sherriff, A Emond, J C Bell, et al. Arch Dis Child 2001;84:480-5.

Adrenaline syringes are vastly over prescribed. D J Unsworth. Arch Dis Child 2001;84:410-11.

An audit of RCP guidelines on DMSA scanning after urinary tract infection. P V Deshpande, K Verrier Jones. Arch Dis Child 2001;84:324-7.

Calibration of the paediatric index of mortality in UK paediatric intensive care units. G A Pearson, J Stickley, F Shann. Arch Dis Child 2001;84:125-8.

If you would like to post an electronic response to these or any other articles published in the journal, please go to the website, access the article in which you are interested, and click on "eLetters: Submit a reponse to this article" in the box in the top right hand corner. 